\title{
PCSP's Diagonal Tie Connectors Thermal Bridges Impact on Energy Performance and Operational Cost: Case Study of a High-Rise Residential Building in Estonia
}

\author{
Martin Kiil ${ }^{1, *}$, Martin-Sven Käärid ${ }^{1}$, Paul Klõšeiko ${ }^{1}$, Karl-Villem Võsa ${ }^{1}$, Raimo Simson ${ }^{1}$, Henri Sarevet ${ }^{1}$, Martin \\ Thalfeldt $^{1}$ and Jarek Kurnitski ${ }^{1,2}$ \\ ${ }^{1}$ Tallinn University of Technology, Department of Civil Engineering and Architecture, Ehitajate tee 5, 19086, Tallinn, Estonia \\ ${ }^{2}$ Aalto University, School of Engineering, Otakaari 4, 02150, Espoo, Finland
}

\begin{abstract}
This study analyses the effect of air circulation around diagonal tie connectors in precast sandwich panels on heating energy demand, energy performance value and heating costs of a sample residential building. Dynamic simulations were performed using 4 different climatic boundary conditions: Estonian test reference year, Estonian 48-year weather dataset as well as data from Eastern Germany and Northern Finland. The results show that the effect of the thermal bridge is most noticeable in total room heating energy demand (increase of $10.3 \%$ ), while the influence on energy performance value was $1.1 \%$. The relative increase of total room heating energy demand was similar (7.0-10.3\%) in all studied climatic regions.
\end{abstract}

\author{
Abbreviations and symbols \\ DTC diagonal tie connector \\ MEP mechanical, electrical and plumbing system \\ nZEB nearly zero energy building \\ PCSP precast concrete sandwich panel \\ $A \quad$ net floor area $\left(\mathrm{m}^{2}\right)$ \\ $E P V \quad$ energy performance value $\left[\mathrm{kWh} /\left(\mathrm{m}^{2} \times \mathrm{a}\right)\right]$ \\ $\Psi \quad$ thermal bridge conductivity $[\mathrm{W} /(\mathrm{m} \times \mathrm{K})]$ \\ $T \quad$ temperature $(\mathrm{K})$ \\ $U$ thermal transmittance $\left[\mathrm{W} /\left(\mathrm{m}^{2} \times \mathrm{K}\right)\right]$ \\ $t_{e} \quad$ external air temperature $\left({ }^{\circ} \mathrm{C}\right)$ \\ $t_{i} \quad$ indoor air temperature $\left({ }^{\circ} \mathrm{C}\right)$ \\ $t_{s} \quad$ supply air temperature $\left({ }^{\circ} \mathrm{C}\right)$
}

\section{Introduction}

The construction industry includes a variety of building components. The demand for high quality, faster and environmentally friendlier construction and energy savings has maintained the need of prefabrication methods. Prefabricating building parts as concrete structures should not be defined only as parts of the structure precast in specialized plants to be assembled afterwards on site. For optimum exploit, precast concrete structure should be designed according to the specific rules from the very outset [1]. Building design involves progressive methods and components to reach high-level building energy performance. Using PCSPs with rigid thermal insulation materials is one option to reach proper building envelope goal of optimal heat transfer.

Investigating the overall thermal performance caused by diagonal tie joints, Klõšeiko et al. [2] found that air cavities around the connectors increased the thermal conductivity of the sample wall up to $55 \%$ (Fig. 1). If no additional insulation around diagonal tie connectors (DTC) is installed, natural air convection occurs in cavities between two insulation sections. However, to evaluate the magnitude of the effect, this paper focuses on delivered room unit heating energy (excluding ventilation heating and domestic hot water) and energy performance value $(E P V)$ analysis with regional climate impact comparison on the example of a typical high-rise residential building in Tallinn.

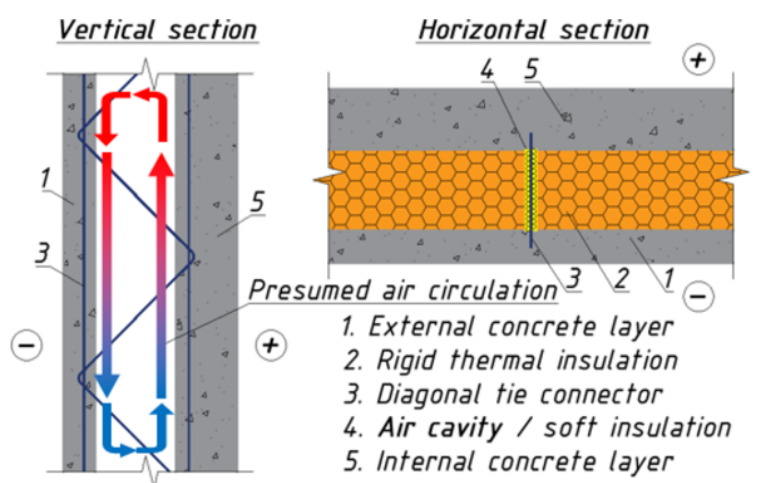

Fig. 1. Stainless steel diagonal tie connector and natural convection between insulation boards (left), additional soft thermal insulation around diagonal tie (right).

\footnotetext{
* Corresponding author: martin.kiil@ taltech.ee
} 
Several studies are available in the field of apartment building energy performance analysis in Estonia. Hamburg et al. [3], [4] claimed measured heating energy to be higher mainly because of higher indoor air temperature $\left(t_{i}\right)$, air handling unit supply air temperature $\left(t_{s}\right)$, using windows for air exchange and higher ventilation rates. During winter months, mean $t_{i}$ $+23^{\circ} \mathrm{C}$ in apartments was measured. Concurrently, Estonian minimum requirements of building energy performance [5] require for calculations and Estonian national annex of EN 16798-1 [6] recommend minimum $t_{i}+21^{\circ} \mathrm{C}$. Being first set in 2007 [7], Estonian energy efficiency related regulations for buildings [5], [8], [9] cover thoroughly the requirements, methods and instructions to calculate energy efficiency for new and significantly reconstructed buildings. Extra cost and economic benefit analysis of energy efficiency conducted by Pikas et al. [10], [11] indicate economic benefits for both small scale and national level. Heating distribution and emission efficiency in residential buildings in Estonia was investigated by Maivel and Kurnitski [12], ventilation performance was well analysed by Mikola [13]. Simson et al. [14] investigated the heat loss effect of calculating methods related to building infiltration in Estonian climate conditions with software IDA ICE [15]. It was found, that the highest risk of under dimensioning is with the 1-storey building as the stack effect with multi storey buildings is more accurate.

The novelty of this study is to expand previous work [2] supported by local residential building research, attainments and construction practice. The target questions in this paper are aimed to determine the impact of the total room heating energy extra losses and operational costs through PCSP DTC $\Psi$ and to assess the impact on the building $E P V$.

\section{Methods}

This section describes the methodical steps (Fig. 3) of the paper in addition to the PCSP' diagonal tie connector
$\Psi$ impact specified by Klõšeiko et al. [2]. Simulation input data for the analysis includes reference object and typical floor plan information described and shown in Fig. 2 and Fig. 4. Tables 1-4 describe simulation input used for building envelope, MEP system and internal gains parameters. Description of the macro used in IDA ICE software [16], based on the Klõšeiko et al [2] Equation 1, is seen on Fig. 5. Simulations section defines the temperature setpoint and climate scenarios (Fig. 6) for regional impact analysis on total room heating energy loss. Different external air temperature curves of Estonian test reference year [17], ASHRAE Fundamentals 2013 weather design data for Berlin, Germany and Rovaniemi, Finland are presented in Fig. 7. Envelope and MEP system parameters for the EPV analysis are shown in Table 5 and Table 6.

\subsection{Simulation input data}

Depending on the specific building parameters, number of similar elements are varied. However, the prefabrication process efficiency depends on the amount of the similar parameters for the product. Therefore, a typical PCSP usage is a high-rise residential building external wall perimeter. The reference building is a modern 14-storey apartment building, built between 2016 and 2019, located in Tallinn, Estonia (Fig. 2). We have analysed a typical floor layout of the building to quantify the effects of PCSP-s.

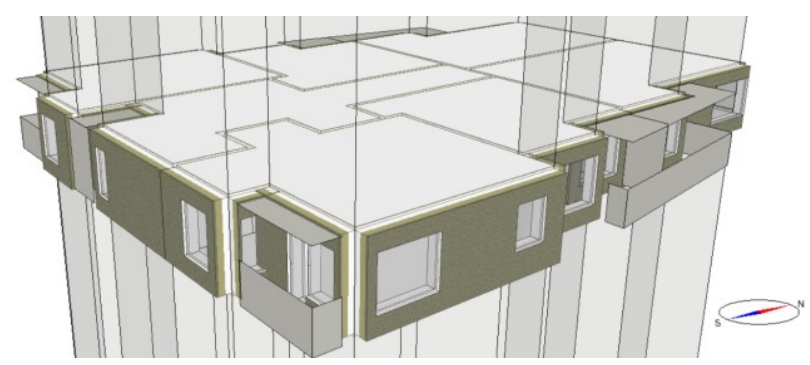

Fig. 2. 3D view of the analysed typical floor plan of the reference building in IDA ICE.

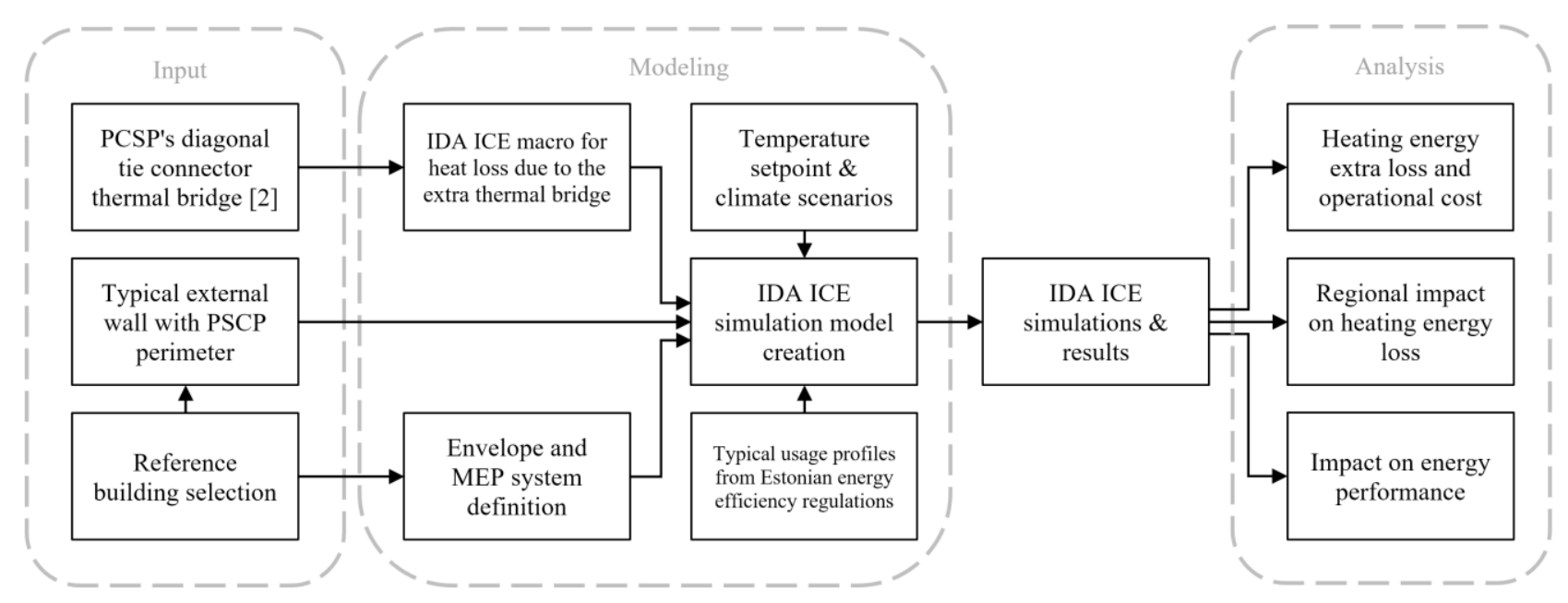

Fig. 3. Flow chart of research methodology. 
The building model was composed and the calculations were conducted using well validated [15] building simulation software IDA ICE, version 4.8 SP1, EQUA Simulation AB, Stockholm, Sweden [16]. The typical floor contains 7 zones with 6 apartments with floor areas from 45 to $70 \mathrm{~m}^{2}$ (Fig. 4).

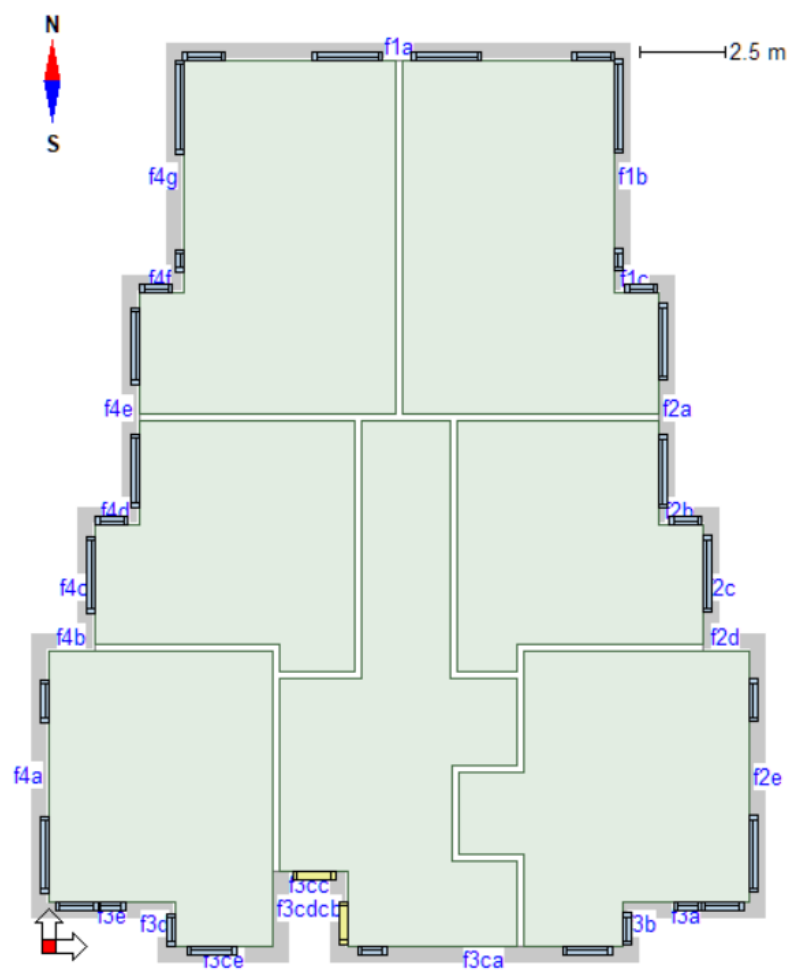

Fig. 4. Typical floorplan layout of the reference building in IDA ICE.

Reference building envelope, thermal bridges and infiltration parameters are listed in Table 1 and 2 . External surface and opening areas were based on design values, as thermal transmittance values were set to meet current low energy building criteria' [5] for $E P V$.

Table 1. Building envelope, thermal bridges and infiltration parameters for reference building base model.

\begin{tabular}{|l|c|c|}
\hline Building envelope & $\begin{array}{c}\text { Surface } \\
\text { area } \\
\left(\mathbf{m}^{\mathbf{2}}\right)\end{array}$ & $\begin{array}{c}\text { Thermal } \\
\text { transmittance } \\
\boldsymbol{U}\left[\mathbf{W} /\left(\mathbf{m}^{\mathbf{2}} \times \mathbf{K}\right)\right]\end{array}$ \\
\hline External wall & 2640 & 0.11 \\
\hline Roof & 420 & 0.10 \\
\hline External floor & 420 & 0.15 \\
\hline $\begin{array}{l}\text { Window (glass solar heat } \\
\text { gain coef. 0.39, visible } \\
\text { transmittance 0.65) }\end{array}$ & 1050 & $\begin{array}{c}0.96 \\
\left(\mathrm{U}_{\mathrm{g}} 0.90,\right. \\
\mathrm{U}_{\mathrm{fr}} 1.5, \\
\text { frame factor } 10 \%)\end{array}$ \\
\hline External door & 70 & 1.01 \\
\hline
\end{tabular}

Linear thermal bridge conductivity and envelope air permeability values were based on regulation recommendations [9]. Building infiltration was modelled as a constant supply air flow rate calculated according to the Estonian methodology [9] from the air permeability value.
Table 2. Thermal bridges and infiltration parameters for reference building base model.

\begin{tabular}{|c|c|c|}
\hline Thermal bridge & $\begin{array}{l}\text { Length } \\
\text { (m) }\end{array}$ & $\begin{array}{c}\text { Linear thermal } \\
\text { bridge conductivity } \\
\Psi[\mathbf{W} /(\mathbf{m} \times \mathbf{K})][9]\end{array}$ \\
\hline $\begin{array}{l}\text { Ext. corner of an ext. } \\
\text { wall }\end{array}$ & 509.6 & 0.20 \\
\hline $\begin{array}{l}\text { Int. corner of an ext. } \\
\text { wall }\end{array}$ & 364.0 & -0.10 \\
\hline $\begin{array}{l}\text { Junction of the roof and } \\
\text { an ext. wall }\end{array}$ & 187.2 & 0.20 \\
\hline $\begin{array}{l}\text { Junction of an ext. wall } \\
\text { and the ext. floor }\end{array}$ & 187.2 & 0.30 \\
\hline $\begin{array}{l}\text { Junction of a window } \\
\text { and an ext. wall }\end{array}$ & 2737.3 & 0.10 \\
\hline $\begin{array}{l}\text { Junction of a ext. door } \\
\text { and an ext. wall }\end{array}$ & 184.8 & 0.10 \\
\hline $\begin{array}{l}\text { Envelope air } \\
\text { permeability }\end{array}$ & \multicolumn{2}{|c|}{$\mathbf{q E}_{\mathbf{E} 50}=2.5\left[\mathbf{m}^{3} /\left(\mathbf{h} \times \mathbf{m}^{2}\right)\right][9]$} \\
\hline
\end{tabular}

Reference building MEP systems, including heating and ventilation, were based on current regulations [5], [9] listed in Table 3. No cooling system was in the reference building design or used in this paper.

Table 3. MEP system parameters [9] for reference building

\begin{tabular}{|c|c|c|}
\hline & & el. \\
\hline & Parameter & Value \\
\hline \multirow{5}{*}{ 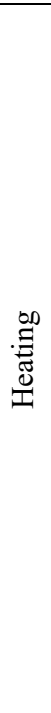 } & $\begin{array}{l}\text { Thermal energy } \\
\text { source }\end{array}$ & $\begin{array}{c}\text { Effective district heating } \\
\text { (Conversion factor } 0.65, \text { efficiency } \\
\text { factor } 0.9)\end{array}$ \\
\hline & $\begin{array}{l}\text { Manner of } \\
\text { room heating }\end{array}$ & $\begin{array}{l}\text { Effective district heating-based, } \\
\text { underfloor heating (Eff. factors of } \\
\text { the distribution and output of heat: } \\
\text { Inserter ceiling }-1.0 \text {, ext. floor - } \\
0.85 \text { ) }\end{array}$ \\
\hline & $\begin{array}{l}\text { Auxiliary } \\
\text { device } \\
\text { electricity }\end{array}$ & $\begin{array}{l}\text { Circulation pumps } \\
1.0\left[\mathrm{kWh} /\left(\mathrm{m}^{2} \times \mathrm{a}\right)\right]\end{array}$ \\
\hline & $\begin{array}{l}\text { Ventilation } \\
\text { heating }\end{array}$ & $\begin{array}{c}\text { Effective district heating-based, } \\
\text { according to climate data, heat } \\
\text { exchanger and min. allowed exhaust } \\
\text { air temp. }\end{array}$ \\
\hline & $\begin{array}{l}\text { Domestic hot } \\
\text { water }\end{array}$ & $\begin{array}{l}\text { Effective district heating-based, } \\
\qquad 30\left[\mathrm{kWh} /\left(\mathrm{m}^{2} \times \mathrm{a}\right)\right]\end{array}$ \\
\hline \multirow{3}{*}{ 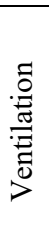 } & $\begin{array}{l}\text { Ventilation } \\
\text { electricity }\end{array}$ & $\begin{array}{c}\text { Air exchange } 0.5\left[1 /\left(\mathrm{s}^{\times} \mathrm{m}^{2}\right)\right] \\
\text { Specific fan power SFP } 1.8 \\
{\left[\mathrm{~kW} /\left(\mathrm{m}^{3} / \mathrm{s}\right)\right](\text { schedule always on })}\end{array}$ \\
\hline & Heat exchanger & Counterflow plate, $\eta=0.8$ \\
\hline & Frost protection & $\begin{array}{l}\text { Min. allowed exhaust air temp. } \\
+5\left({ }^{\circ} \mathrm{C}\right)\end{array}$ \\
\hline
\end{tabular}

To assess actual total room heating energy extra loss and calculate $E P V$ [9], internal heat gains such as occupants, lighting and appliances must be taken into account in simulations. Internal heat gain values and time schedules are presented in Table 4. 
Table 4. Building internal gains parameters and schedules [9] for reference building base model.

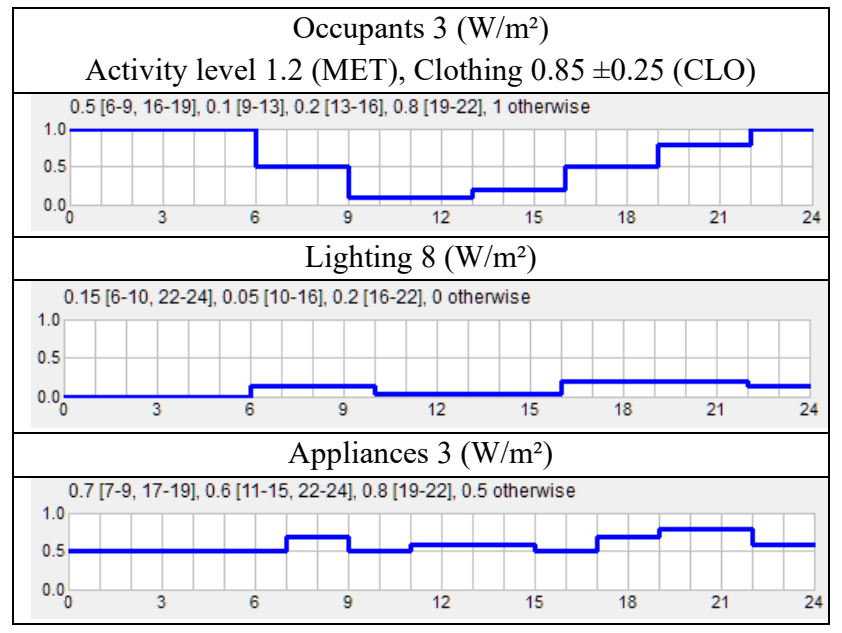

Klõšeiko et al. [2] described the extra loss for DTC as an empiric equation of $\Psi$ per one connector (including steel element). Formula (Equation 1) accounts for $10 \mathrm{~mm}$ wide air gap between insulation boards at the diagonal tie connector when $200 \mathrm{~mm}$ PIR insulation is used.

$$
\Psi=\left(3.73 \times 10^{-4}\right) \Delta T+1.37 \times 10^{-2}
$$

where $\Delta T$ is the temperature difference between $t_{i}$ and $t_{e}$. The macro scheme for the extra room heating energy loss calculation for each zone in IDA ICE is shown in Fig. 5. These 7 macros are placed as one overall macro into the IDA ICE "Standard Plant" and the extra heat losses are merged with base model total room heating energy.

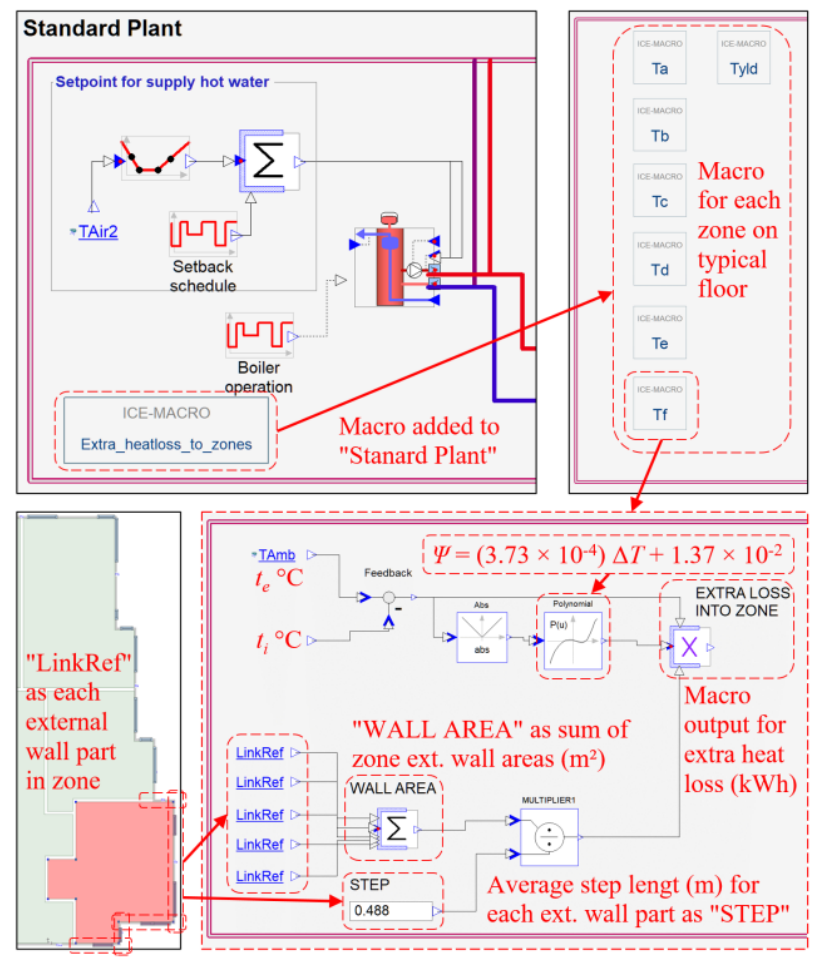

Fig. 5. IDA ICE macro for heat loss due to the diagonal tie connector extra thermal bridge.
The extra heat loss described in Fig. 5, includes "TAmb" as $t_{e}$, "Polynomal" as the function of Equation 1, "LinkRef" as the wall surface area $\mathrm{m}^{2}$ per each external wall and "Step" as the average step between DTCs. Although the default step for DTCs is $0.6 \mathrm{~m}$, an average step length was calculated for each apartment and the hallway and entered separately into macros.

\subsection{Simulations}

Estonian local climate data used in this study was based on Estonian test reference year [17]. Long-term data based on climate from Tõravere, Tartu weather station from years 1970 to 2018, was used to assess the amplitude of the deviation between different decades. Reference building with the same input parameters was also simulated in more varied climate regions. For colder weather Rovaniemi, Finland and for warmer weather Berlin, Germany were used according to ASHRAE Fundamentals 2013 weather design data [16]. Thus, simulations with 2 different $t_{i}$ and $t_{s}$ variables using 4 different climatic boundary conditions were conducted (Fig. 6). External air temperature duration curves for EstonianTRY, Eastern Germany and Northern Finland are shown on Fig. 7.

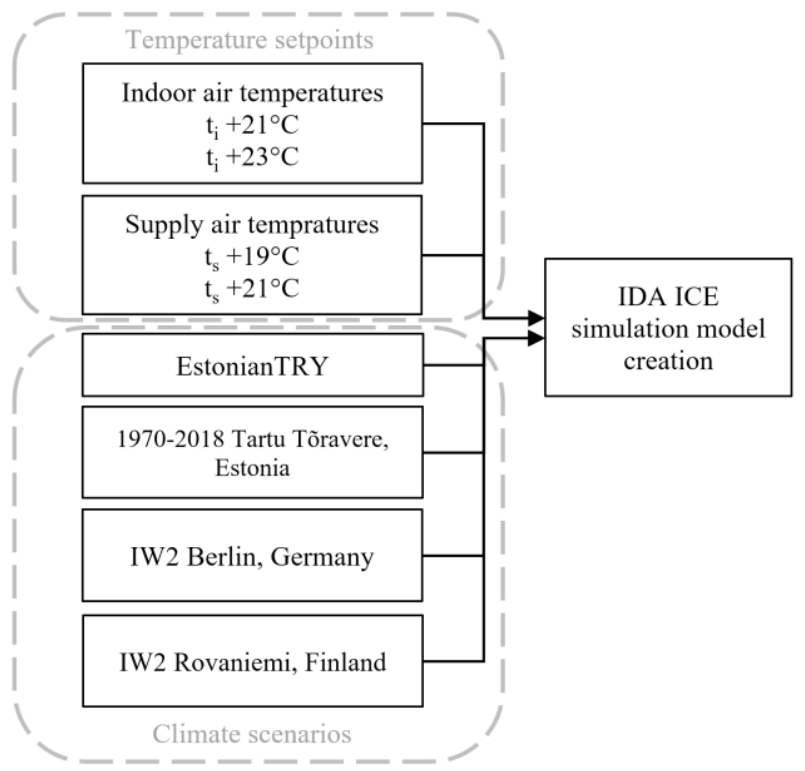

Fig. 6. Temperature setpoint and climate scenarios.

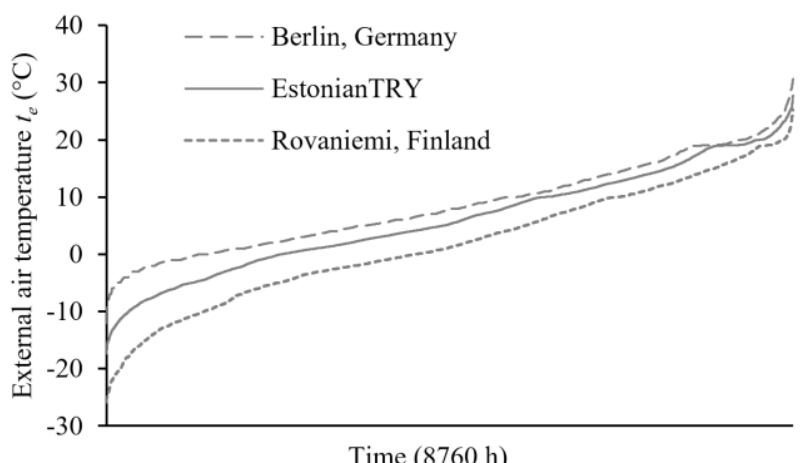

Fig. 7. External air temperature duration curves for regional impact analysis. 
In addition to assessing impact on $E P V$ in comparison of reference building base model and DTC extra loss, thermal energy sources and a sample of envelope and MEP parameter variations were analysed. Base model thermal energy source as an effective district heating is described in Table 3. For the purposes of the current regulation [5], efficient district heating (or cooling) is described as: "A district heating system that uses at least $50 \%$ renewable energy, $50 \%$ waste heat, $75 \%$ cogeneration or $50 \%$ combination of such energy and heat". Other thermal energy source options with differences between reference building base model, including default district heating, pellet boiler, oil and gas condensing boiler, solid fuel and peat boiler, air-towater and geothermal heat pumps, are listed in Table 5.

Table 5. Regulation energy carrier conversion factors [5] with efficiency factors of thermal energy sources on the basis of the lowest calorific value of the consumable substance of the fuel

[9] parameters for comparison with the base model.

\begin{tabular}{|c|c|}
\hline $\begin{array}{l}\text { Thermal } \\
\text { energy source }\end{array}$ & $\begin{array}{c}\text { Changes compared to reference } \\
\text { building base model }\end{array}$ \\
\hline District heating & Conv. factor 0.9 \\
\hline Pellet boiler & Conv. factor 0.65 , eff. factor 0.85 \\
\hline $\begin{array}{l}\text { Oil, condensing } \\
\text { boiler }\end{array}$ & Conv. factor 1.0 , eff. factor 0.90 \\
\hline $\begin{array}{l}\text { Gas, condensing } \\
\text { boiler }\end{array}$ & Conv. factor 1.0 , eff. factor 0.95 \\
\hline Solid fuel boiler & Conv. factor 1.0, eff. factor 0.75 \\
\hline Peat boiler & Conv. factor 1.0 , eff. factor 0.75 \\
\hline $\begin{array}{l}\text { Air-to-water } \\
\text { heat pump }\end{array}$ & $\begin{array}{c}\text { Conv. factor } 2.0 \text {, eff. factor } 1.0 \\
\text { Aux. dev. electricity } 0.0\left[\mathrm{kWh} /\left(\mathrm{m}^{2} \times \mathrm{a}\right)\right] \\
\text { Heat pump ratio } 0.78 \\
\text { COP room heating } 2.9 \\
\text { COP ventilation heating } 2.7 \\
\text { COP domestic hot water } 2.0\end{array}$ \\
\hline $\begin{array}{l}\text { Geothermal heat } \\
\text { pump }\end{array}$ & $\begin{array}{c}\text { Conv. factor } 2.0 \text {, eff. factor } 1.0 \\
\text { Aux. dev. electricity } 0.0\left[\mathrm{kWh} /\left(\mathrm{m}^{2} \times \mathrm{a}\right)\right] \\
\text { Heat pump ratio } 0.96 \\
\text { COP room heating } 4.4 \\
\text { COP ventilation heating } 4.0 \\
\text { COP domestic hot water } 2.7\end{array}$ \\
\hline
\end{tabular}

The sample of envelope and MEP parameter variations was analysed in this study. Ventilation system options included comparison of electrical ventilation heating for central air handling unit and rotary heat exchanger comparison instead of plate for apartmentbased air handling unit. The current regulation [5] allows $0.421 /\left(\mathrm{s} \times \mathrm{m}^{2}\right)$ air exchange rate instead of 0.5 if air exchange rate can be controlled in the boundaries of the single apartment. Manner of room heating type was changed from underfloor heating system to radiator. Window thermal transmittance was reduced by $9 \%$. Infiltration was lowered to least allowed value by regulation, as if it is planned to measure the air leakage during the construction of the building [9]. Electrical domestic hot water system and $25 \%$ lower lighting installed power per $\mathrm{m}^{2}$ options were analysed. The differences between reference building base model and a sample of envelope and MEP parameters analysed for the comparison are listed in Table 6.

District heating is used as a basis for operational cost analysis. The district heating price used in this paper is $58.8 € / \mathrm{MWh}$ including (49€/MWh without) VAT[18].

Table 6. Regulation methodology's [9] component sensitivity analysis example parameters for comparison with the base model.

\begin{tabular}{|c|c|}
\hline Parameter & $\begin{array}{c}\text { Changes compared to } \\
\text { reference building base model }\end{array}$ \\
\hline $\begin{array}{l}\text { Electrical ventilation } \\
\text { heating }\end{array}$ & $\begin{array}{l}\text { Conv. factor } 2.0, \\
\text { eff. factor } 1.0\end{array}$ \\
\hline $\begin{array}{l}\text { Apartment-based air } \\
\text { handling unit with plate } \\
\text { heat exchanger }\end{array}$ & $\begin{array}{c}\text { Conv. factor } 2.0 \text {, eff. factor } 1.0 \\
\text { Air exchange } 0.42\left[1 /\left(\mathrm{s} \times \mathrm{m}^{2}\right)\right] \\
\text { Min. allowed exhaust } \\
\text { air temp. } 0\left({ }^{\circ} \mathrm{C}\right)\end{array}$ \\
\hline $\begin{array}{l}\text { Apartment-based air } \\
\text { handling unit with } \\
\text { rotary heat exchanger }\end{array}$ & 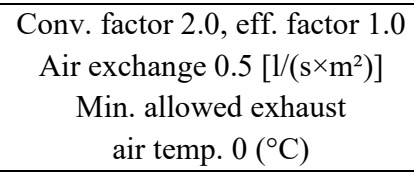 \\
\hline $\begin{array}{l}\text { Manner of room heating } \\
\text { radiator heating system }\end{array}$ & $\begin{array}{c}\text { Distr. output eff. factor } 0.97 \\
\text { Circulation pumps } \\
1.0\left[\mathrm{kWh} /\left(\mathrm{m}^{2} \times \mathrm{a}\right)\right] \\
\end{array}$ \\
\hline $\begin{array}{l}\text { Window thermal } \\
\text { transmittance } U\end{array}$ & $\begin{array}{c}0.87\left[\mathrm{~W} /\left(\mathrm{m}^{2} \times \mathrm{K}\right)\right] \\
\left(\mathrm{U}_{\mathrm{g}} 0.80\left[\mathrm{~W} /\left(\mathrm{m}^{2} \times \mathrm{K}\right)\right]\right)\end{array}$ \\
\hline $\begin{array}{l}\text { Envelope air } \\
\text { permeability }\end{array}$ & $\mathrm{qE} 50=1.5\left[\mathrm{~m}^{3} /\left(\mathrm{h} \times \mathrm{m}^{2}\right)\right]$ \\
\hline $\begin{array}{l}\text { Electrical domestic hot } \\
\text { water }\end{array}$ & Conv. factor 2.0, eff. factor 1.0 \\
\hline Lighting & $6\left(\mathrm{~W} / \mathrm{m}^{2}\right)$ \\
\hline
\end{tabular}

\section{Results and discussion}

In this paper, room heating energy extra loss and operational cost, regional impact on room heating energy loss and impact on energy performance, due to the PCSP's DTC extra thermal bridge was analysed. General DTC room heating energy extra loss is in Estonia 10.3\% (12.6 MWh/a), in Berlin, Germany 10.2\% (8.2 MWh/a) and in Rovaniemi, Finland 8.0\% (16.5 MWh/a) (Fig. 8).

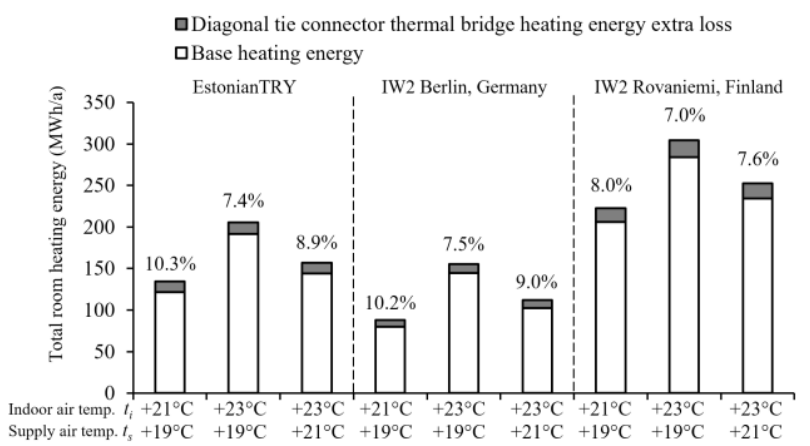

Fig. 8. Comparison of heating energy and diagonal tie connector thermal bridge heating energy extra loss with indoor and supply air \& climate scenarios of Estonian test reference year, IW2 Berlin, Germany and Rovaniemi, Finland. Percentage calculated as increase of base model. 
As the temperature setpoints for $t_{i}$ are $t_{s}$ are increased, the extra room heating energy percentages decrease and absolute values increase similarly in each climate region. Without DTC extra loss, using more common $t_{i}+23^{\circ} \mathrm{C}$ for indoor air temperature, total room heating energy increases $57.2 \%$ in Estonia. It increases the most in Berlin, Germany by $80.7 \%$ and $37.8 \%$ in Rovaniemi, Finland as being more sensitive in warmer climate and less sensitive in colder climate region. In the context of Estonia for the smaller $\left(45 \mathrm{~m}^{2}\right)$ apartment the DTC extra loss results express $6.78 €$ (including partial general area $1.12 €)$ and for the larger $\left(70 \mathrm{~m}^{2}\right)$ apartment $10.55 €$ (including partial general area $1.74 €$ ) annual additional billings. The extra billings for higher $t_{i}+23^{\circ} \mathrm{C}$ instead of $+21^{\circ} \mathrm{C}$ room heating energy is approximately 6 times higher than the DTC extra loss per $\mathrm{m}^{2}$. The simulation results based on long-term weather data from Tartu, Tõravere show total room heating energy decrease tendency through decades (Fig. 9). Simulations show extra room heating energy need due to the DTC thermal bridge from 1.51 to $2.51 \mathrm{kWh} /\left(\mathrm{m}^{2} \times \mathrm{a}\right)$ with reference building base model. The range for higher indoor air temperature $t_{i}+23^{\circ} \mathrm{C}$ is from 1.95 to $3.04 \mathrm{kWh} /\left(\mathrm{m}^{2} \times \mathrm{a}\right)$ and for both higher indoor air temperature $t_{i}+23^{\circ} \mathrm{C}$ and $t_{i}+19^{\circ} \mathrm{C}$ is from 1.83 to $2.89 \mathrm{kWh} /\left(\mathrm{m}^{2} \times \mathrm{a}\right)$.

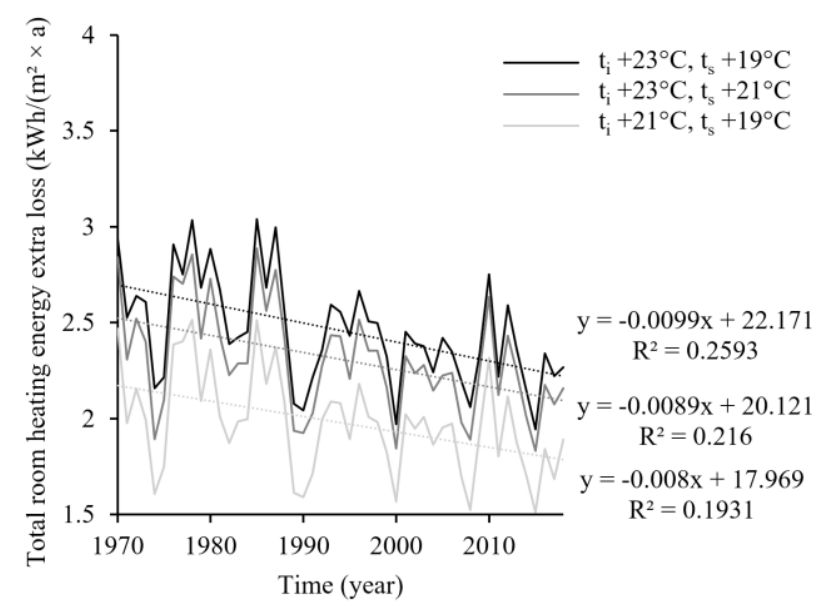

Fig. 9. Total room heating energy extra loss according to Tartu Tõravere weather data 1970-2018.
Comparison with other 3 climate regions is presented in Fig. 10. For Tartu, Tõravere, minimum and maximum are at the end of the whiskers, the lower and upper line of the box are the first and the third quartiles, the line between is median and the cross shows mean value of the simulation results. Other 3 climate data results are shown only with line and crossing as equal values for one year-based simulation. The results presented on Fig. 10 have similar proportions with Fig. 8 for different climate regions. For Estonian test reference year, the results are $2.14,2.40$ and $2.19 \mathrm{kWh} /\left(\mathrm{m}^{2} \times \mathrm{a}\right)$ as an extra room heating energy due to the DTC thermal bridge. For Berlin, the results are 1.39, 1,84 and 1.58 $\mathrm{kWh} /\left(\mathrm{m}^{2} \times \mathrm{a}\right)$ and for Rovaniemi $2.80,3.41$ and 3.06 $\mathrm{kWh} /\left(\mathrm{m}^{2} \times \mathrm{a}\right)$.

The analysis of the impact on energy performance made on the reference building base model include three comparisons. The first comparison of the base model $121.4 \mathrm{kWh} /\left(\mathrm{m}^{2} \times \mathrm{a}\right) \quad$ with DTC extra loss 122.8 $\mathrm{kWh} /\left(\mathrm{m}^{2} \times \mathrm{a}\right)$ showed $1.1 \%$ increase for $E P V$ remaining under low energy building criteria $\left(125 \mathrm{kWh} /\left(\mathrm{m}^{2} \times \mathrm{a}\right)\right)$.

The second comparison consisted of the base model with the regulation energy carrier factors with efficiency factors of thermal energy source on the basis of the lowest calorific value of the consumable substance of the fuel. The results showed EPV decrease (4.9\%) with geothermal heat pump. Other option $E P V$-s increased, of which only pellet boiler with $(2.2 \%)$ maintained the required low energy building criteria. Default district heating increased $14.1 \%$, following gas condensing boiler with $16.8 \%$, air-to-water heat pump with $17.8 \%$ and oil condensing boiler with $19.8 \%$. Both solid fuel and peat boiler $E P V$-s increased $31.1 \%$. Compared to DTC extra loss EPV increase (1.1\%), the pellet boiler option $(2.2 \%)$ is the most similar. Regarding geothermal heat pump decrease $(4.9 \%)$, all other options $(14.1-31.1 \%)$ are more than 10 times sensitive to the increase of EPV than DTC heat loss.

The third comparison included a sample of parameter changes for the component sensitivity analysis on $E P V$. Lowering installed lighting wattage resulted in $2.4 \%$ decrease on EPV. Switching to lower window thermal transmittance value $(0.9 \%)$, determining a lower envelope air permeability $(0.8 \%)$ and switching to radiators $(0.6 \%)$ also helped to gain a better $E P V$.

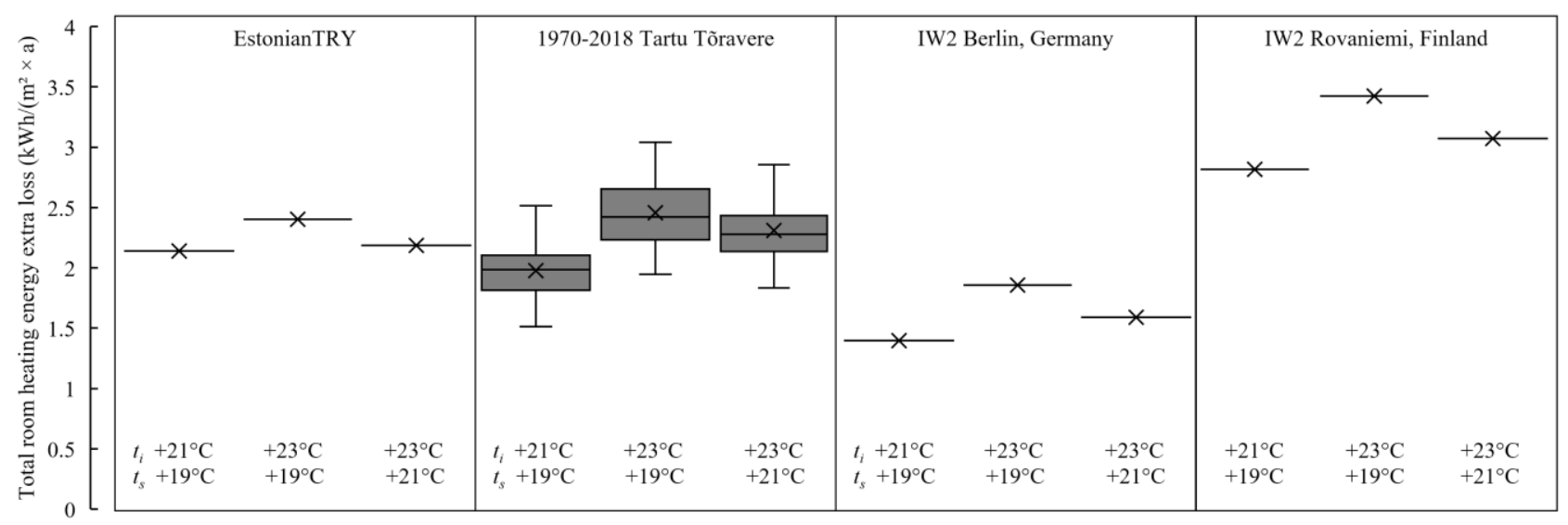

Fig. 10. Total room heating energy extra loss deviation according to Estonian test reference year, Tartu Tõravere weather data 19702018, IW2 Berlin, Germany and Rovaniemi, Finland. 
Apartment-based rotary heat exchanger $(0.6 \%)$ and plate exchanger (7.2\%) equipped air handling units as well as using electrical ventilation heater $(13.7 \%)$ for central air handling unit, achieved a higher EPV. Replacing the domestic hot water system with electrical heating, the increase (29.7\%) is the highest from the third comparison, being smaller than second comparison worst options as solid fuel or peat boilers (31.1\%). Changes to apartment-based rotary heat exchanger equipped air handling unit, switching to radiators, lowering window thermal transmittance and air leakage values maintain the similar percentage to the $E P V$ as DTC extra loss.

The second and third comparison show illustratively, how small parameter changes in the calculations of building energy performance can change rapidly the overall results of $E P V$. Combining DTC extra loss with other options from second or third comparison merge the outcome of decrease or increase of the EPV. However, reaching high expectancy goals on building energy performance for low energy and nearly zero energy building (nZEB) requirements, all building envelope and MEP parameters must be taken into account.

Fig. 11 also indicates, that reaching nZEB requirement $\left(105 \mathrm{kWh} /\left(\mathrm{m}^{2} \times \mathrm{a}\right)\right)$ without producing energy on-site (e.g. with photovoltaic panels) is rather difficult. According to the prerequisite set for reaching nZEB $E P V$, only 2 options from the second comparison and 5 options from third comparison of the $E P V$ analysis maintain the assumption for meeting minimum requirements for new buildings in Estonia. It is a substantial, that the reference building base model in this study meets the low energy building criteria, with rather exemplary envelope and MEP system parameters available. This includes the PCSP with $200 \mathrm{~mm}$ layer of PIR insulation material with a low thermal transmittance value of $0.11 \mathrm{~W} /\left(\mathrm{m}^{2} \times \mathrm{K}\right)$. Therefore, ensuring low thermal transmittance value, PCSP's diagonal tie connector joints must be properly insulated to be consistent with calculated thermal transmittances or additional room heating energy losses must be taken into account in energy calculations.

This study was based only on one sample building analysis. Therefore, more case studies need to be investigated for more solid conclusions regarding building extra room heating energy due to the DTC thermal bridge with operational cost analysis. In addition, simplification for insulation material as PIR was made, as it is forbidden to use it in high-rise buildings in Estonia due to the fire safety regulation [19]. Further research should also include manufacturing extra cost analysis for ensuring high quality DTC insulation methods during PCSP production.

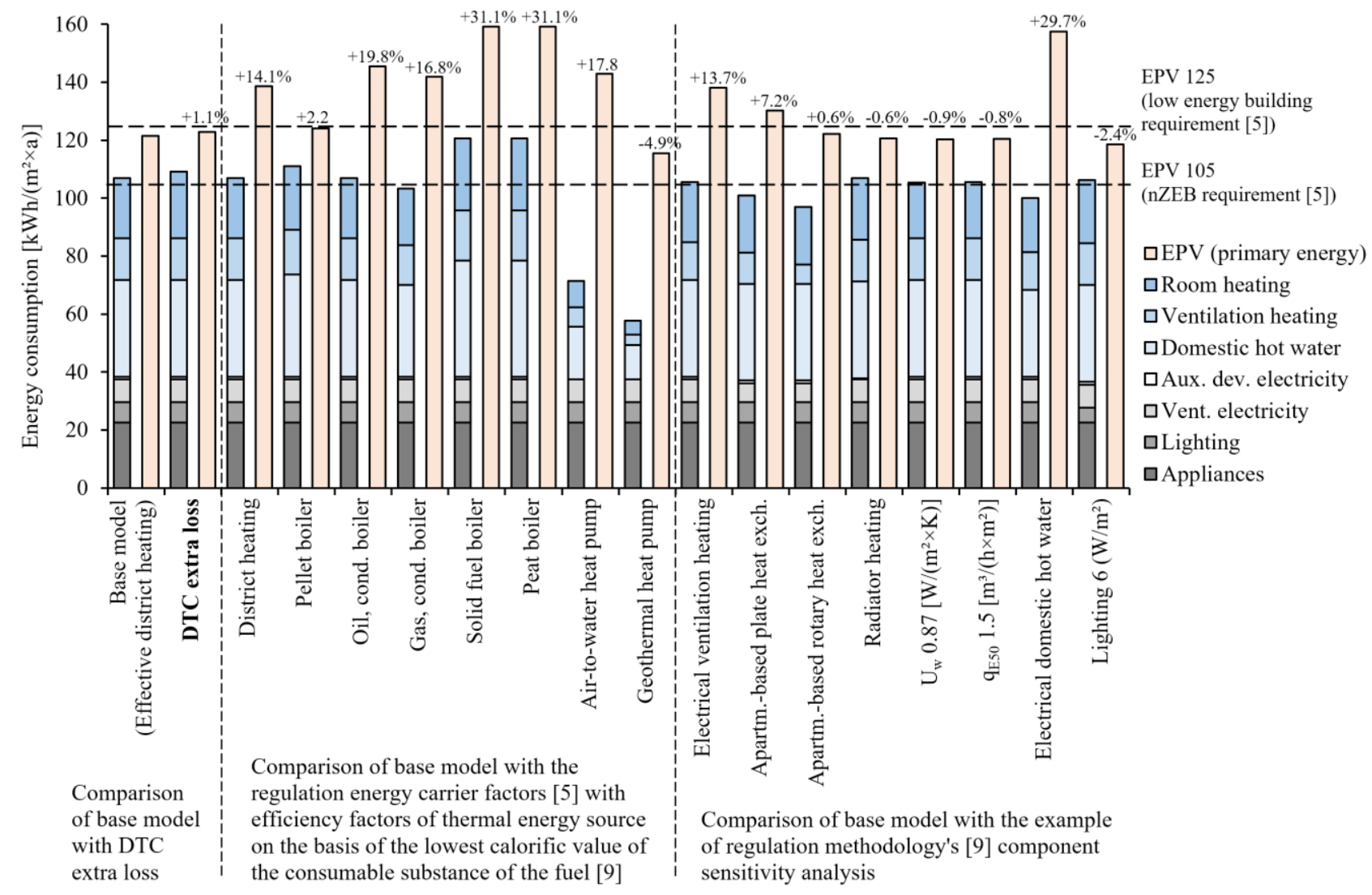

Fig. 11. Comparison of base model with diagonal tie connector thermal bridge room heating energy extra loss, with regulation energy carrier conversion factors [5] with efficiency factors of thermal energy sources on the basis of the lowest calorific value of the consumable substance of the fuel [9] and with the example of regulation methodology's [9] component sensitivity analysis. Percentage calculated as increase of base model. 


\section{Conclusions}

The aim of this paper is to fill the gap of the energy performance and energy operational cost impact for PCSP's diagonal tie connector $\Psi$ analysis results. In Estonian climate the thermal bridge caused an increase of total room heating energy of $10.3 \% \quad(2.14$ $\left.\mathrm{kWh} /\left(\mathrm{m}^{2} \times \mathrm{a}\right)\right)$. The effect on energy performance value of the studied building was lower at $1.39 \mathrm{kWh} /\left(\mathrm{m}^{2} \times \mathrm{a}\right)$, which accounted for $1.1 \%$ of the whole $E P V$. The influence on the annual room heating costs was relatively minor at $6.78 € / \mathrm{a}$ increase per $45 \mathrm{~m}^{2}$ apartment and $10.55 € / \mathrm{a}$ per $70 \mathrm{~m}^{2}$ apartment. The additional room heating energy and cost effect increased, when indoor air temperature setpoint is risen form standardized $+21^{\circ} \mathrm{C}$ to more common $+23^{\circ} \mathrm{C}$. Analysis using 48 -year Estonian climate data showed that the effect is decreasing over time. Regional climate impact analysis results exhibited larger effect in colder climate in Rovaniemi, Finland and smaller effect in warmer climate in Berlin, Germany. However, the share of extra losses was relatively similar: in the range of $7.0-10.3 \%$ for all studied regions.

In conclusion, we consider that PCSP's diagonal tie connector joints must be either:

a) properly insulated to be consistent with calculated thermal transmittances, or

b) additional losses must be taken into account in energy calculations.

This research was supported by the Estonian Centre of Excellence in Zero Energy and Resource Efficient Smart Buildings and Districts, ZEBE (grant 2014-2020.4.01.15-0016; grant TK146) funded by the European Regional Development Fund, by the programme Mobilitas Pluss (Grant No - 20142020.4.01.16-0024, MOBTP88) and by the European Commission through the H2020 project Finest Twins (grant No. 856602), the Estonian Research Council grant (PSG409) and by the Personal research funding grant (PRG483). The authors are grateful for the initial data provided by the developer, constructor and the PCSP manufacturer and for the Estonian Weather Service for the long-term weather data.

\section{References}

1. FIP, Planning and design handbook on precast building structures. SETO Ltd, 1998

2. P. Klõšeiko, R. Piir, M. Jeltsov, and T. Kalamees, in 12th Nordic Symposium on Building Physics, NSB2020, 2020

3. A. Hamburg, K. Kuusk, A. Mikola, and T. Kalamees, Energy 194, 116874 (2020)

4. A. Hamburg and T. Kalamees, Energy Build. 199, 332-341 (2019)

5. Ministry of Economic Affairs and Communications, State Gazette, 2018

6. EVS/TC 27, Estonian Centre for Standardisation, 2019.

7. Government of the Republic, 2007

8. Ministry of Economic Affairs and Communications, State Gazette, 2015

9. Ministry of Economic Affairs and
Communications, State Gazette, 2015

10. E. Pikas, M. Thalfeldt, J. Kurnitski, and R. Liias, Energy 84, 623-633 (2015)

11. E. Pikas, J. Kurnitski, R. Liias, and M. Thalfeldt, Energy Build. 86, 151-160 (2015)

12. M. Maivel and J. Kurnitski, Energy Build. 69, 224-236 (2014)

13. A. Mikola, T. Kalamees, and T.-A. Kõiv, Energy Procedia 132, 963-968 (2017)

14. R. Simson, T. Rebane, M. Kiil, M. Thalfeldt, and J. Kurnitski, in 12th Nordic Symposium on Building Physics, NSB2020, 2020

15. S. Kroph and G. Zweifel, HLK Engineering, Hochschule Technik, Architektur Luzern., 2002

16. EQUA, 2019. [Online]. Available: www.equa.se.

17. T. Kalamees and J. Kurnitski, 40-58 (2006)

18. Utilitas Energy Group, [Online]. Available: https://www.utilitas.ee/soojuse hinnad/

19. Ministry of the Interior, State Gazette, 2017 